\title{
Development of Equipment for Testing of Heat Pipes
}

\author{
Vladimir A. Kulagin*a and Nikita Y. Sokolova, b \\ ${ }^{a}$ Siberian Federal University \\ 79 Svobodny, Krasnoyarsk, 660041, Russia \\ ${ }^{b} \mathrm{AO}$ «Information Satellite Systemsthem \\ Academician M.F. Reshetnev» \\ 52 Lenin Str., Zheleznogorsk, 662972, Russia
}

Received 17.04.2015, received in revised form 26.05.2015, accepted 04.06.2015

Presents the results creation of a new workplace for testing of heat pipes and giperteploprovodyaschih sections (GTPS) to ensure the accuracy of the measurements the temperature difference accurate to $0.1{ }^{\circ} \mathrm{C}$ between zones of condensation, evaporating GTPS. Is shown a simplified cooling system. Is noted that the cost of the new installation verification GTPS 15 to 20 times smaller than the existing ones.

Keywords: giperteploprovodyaschie section, test the heat pipes, space vehicles, improvement of test equipment.

DOI: $10.17516 / 1999-494 X-2015-8-6-774-785$.

\section{Разработка оборудования}

\section{для тестирования тепловых труб}

\author{
В.А. Кулагин ${ }^{\mathrm{a}}$, Н.Ю. Соколов ${ }^{\mathrm{a}, \boldsymbol{\sigma}}$ \\ ${ }^{a}$ Сибирский федеральный университет \\ Россия, 660041, Красноярск, Свободный, 79 \\ ${ }^{\sigma}$ АО «Информационные спутниковые системь \\ им. академика М.Ф. Решетнёва» \\ Россия, 662972, Железногорск, ул. Ленина, 52
}

Изложены результаты создания нового рабочего места для испьтаний тепловых труб и гипертеплопроводящих секций (ГТПС) с целью обеспечения точности измерений разниџь температур с точностью до $0.1{ }^{\circ} \mathrm{C}$ между зонами конденсаичи, испарения ГТПС. Показано упрощение системы охлаждения. Отмечено, что стоимость новой установки по проверке ГТПС в 15-20 раз меньше, чем сущуествующие.

Ключевые слова: гипертеплопроводящче секции, испытания тепловых труб, космические аппараты, совершенствование испьтательного оборудования.

(C) Siberian Federal University. All rights reserved

* Corresponding author E-mail address: v.a.kulagin@mail.r 


\section{Введение}

Перспективы развития информационных спутниковых систем в России связаны с созданием негерметичных космических аппаратов (КА). Такие аппараты уже вошли в состав глобальной навигационной системы ГЛОНАСС и в недалеком будущем станут ее основой. Одновременно идет разработка новых моделей КА с увеличенной мощностью более 5 кВт, сроком активного существования более 12 лет и с повышенными точностными навигационновременными характеристиками [1].

Одной из главных проблем является обеспечение оптимального теплового режима радиоэлектронной аппаратуры (РЭА) на борту КА. В условиях постоянно возрастающей мощности бортовой аппаратуры и необходимости уменьшения ее объема и массы обеспечение работы КА возможно только за счет увеличения эффективности работы систем отвода тепла.

Основной принцип функционирования системы обеспечения теплового режима заключается в поддержании требуемого диапазона температур на посадочных местах тепловыделяющего оборудования космического аппарата КА при заданных энергопотреблениях. От этого зависит долговечность и надежность функционирования спутника в целом. Для минимизации массоэнергетических параметров системы целесообразно использовать принцип естественной, нерегулируемой передачи тепловой мощности с более высокого температурного уровня на низкий. Это обеспечивается отбором тепловой мощности, выделяемой аппаратурой, от ее посадочных мест на термоплатах (панелях), передачей этой мощности на радиационный теплообменник (РТО) и отводом ее с РТО в окружающее пространство. Наиболее предпочтительным средством реализации этого принципа являются тепловые трубы (ТT), работающие на основе замкнутого испарительно-конденсационного цикла. ТТ отличаются высокой эффективной теплопроводностью, в десятки раз превышающей теплопроводность металлов [2]. Это позволяет оптимально решать многие инженерные задачи, связанные с передачей тепла с минимальными потерями, охлаждением и термостатированием или термостабилизацией различных объектов, использующихся как на Земле, так и в космическом пространстве.

Важно также развитие методов экспериментального исследования гидродинамики двухфазного газожидкостного течения в микроканале, получение закономерностей режимов течения и определение границ режимов течения, определение потерь на трение для каналов с различной ориентацией относительно вектора силы тяжести [3]. Современные искусственные спутники Земли для связи и телерадиовещания представляют собой КА, оснащенные крупногабаритным негерметичным приборным отсеком в виде блочно-модульной конструкции на основе плоских прямоугольных сотовых панелей [4], несущих на себе теплонагруженные приборы радиоэлектронной бортовой аппаратуры (БА) [5].

Отсутствие в конструкциях ТТ движущихся механических частей, использование для движения теплоносителя только малых капиллярных сил, высокая плотность передаваемого теплового потока при минимальных перепадах температур (термических сопротивлениях) и автономность работы каждой из них, возможность резервирования, минимальное обслуживание и малый удельный вес, бесшумная работа создают им преимущества и обеспечивают надежность и долговечность перед иными способами термостатирования заданного объекта на борту КА. Панели с вмонтированными в них ТТ - надежная защита от ударов микрометеоритов [2].

$$
-775-
$$


Изотермализирующая природа ТТ уменьшает температуры мощных компонентов тепловыделяющего оборудования, увеличивая таким образом надёжность их работы. Выигрыш в массе даёт возможность распределения массы КА в пользу систем энергопитания, двигателей и полезной нагрузки [6]. Существуют различные методы проверки работоспособности ТT термовакуумные испытания (ТВИ) каждого образца, экспресс-контроль в составе РЭА и т.п. В этой связи важным является совершенствование испытательного оборудования, обеспечивающего высокую точность определения характеристик ТТ, что в итоге обеспечит надежность и долговечность работы КА на орбите.

\section{Методика проведения испытаний ТT и результаты моделирования}

Т-образная плоская тепловая труба, или гипертеплопроводящая секция (ГТПС), - это пакет мини-тепловых труб, заключенных в одном герметичном корпусе. ГТПС предназначены для охлаждения радиоэлектронной аппаратуры космических аппаратов, а также могут быть использованы в любых отраслях промышленности, где необходим быстрый сброс тепла или выравнивание теплового поля [7]. В табл. 1 и на рис. 1 отражены основные характеристики ГТПС и ее монтаж в составе блока прибора.

Существует проблема точного определения эффективной теплопроводности ГТПС, сложность заключается в следующем:

- разница температур между зонами конденсации и испарения менее $2{ }^{\circ} \mathrm{C}$;

- необходимость проведения измерения в двух точках одновременно;

- необходимость стабилизации температуры системы охлаждения;

- требование сохранить поверхности ТТ без механических повреждений.

Сложность определения работоспособности ГТПС с приклеенными к зоне испарения печатными платами (ПП) состоит еще и в том, что на ПП нельзя наносить термопасту, поскольку полное её удаление проблематично, а в случае если на ПП уже установлены РЭА, то невозможно.

Таблица 1. Основные характеристики ГТПС

\begin{tabular}{|c|l|c|}
\hline № п/п & \multicolumn{1}{|c|}{ Наименование параметра } & \multicolumn{1}{|c|}{ Значение } \\
\hline 1 & $\begin{array}{l}\text { Эффективная теплопроводность, Вт/мК: } \\
\text { при } 25^{\circ} \mathrm{C} \\
\text { при } 60^{\circ} \mathrm{C}\end{array}$ & $\begin{array}{c}\text { До } 14000 \\
\text { До } 25000\end{array}$ \\
\hline 2 & $\begin{array}{l}\text { При подведении теплового потока мощностью 50 Вт градиент температур } \\
\text { между зоной испарения и зоной конденсации в рабочем интервале } \\
\text { температур от } 18 \text { до } 60^{\circ} \mathrm{C}\end{array}$ & Менее 2 \\
\hline 3 & \begin{tabular}{l} 
Теплоноситель \\
\hline 4
\end{tabular} & Стойкость к ионизирующему излучению космического пространства, рад \\
\hline 5 & Суммарная негерметичность секций, л мм.рт.ст./с $1 \cdot 10^{7}$ & Вода \\
\hline 6 & Срок службы, лет & $1 \cdot 10^{-4}$ \\
\hline 7 & Толщина, мм & 25 \\
\hline
\end{tabular}




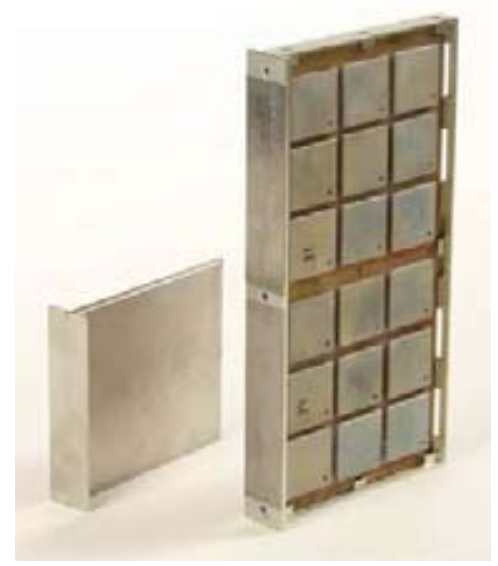

Рис. 1. ГТПС в составе блока прибора

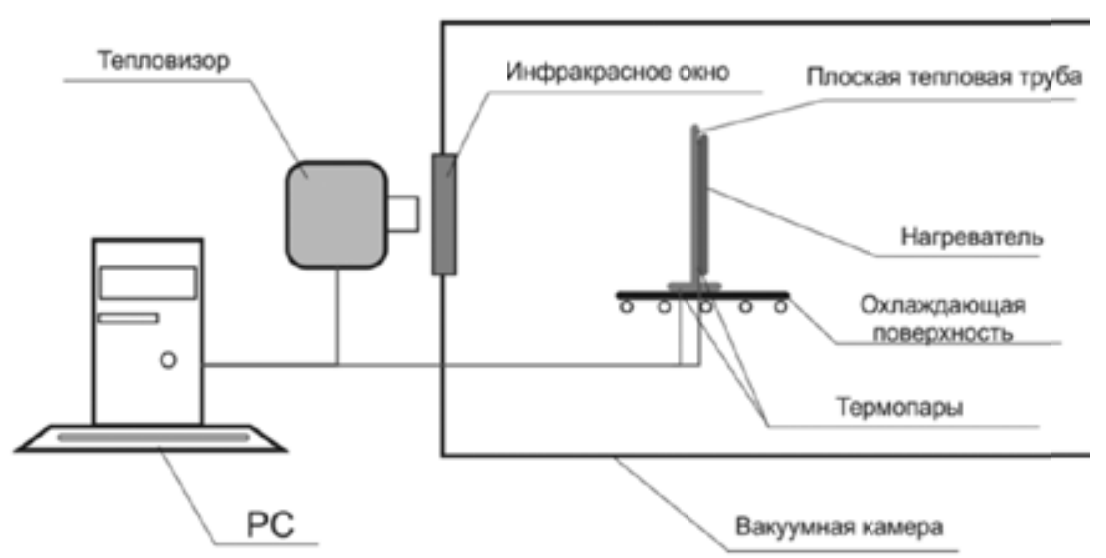

Рис. 2. Схема рабочего места по исследованию характеристик Т-образной плоской тепловой трубы

Автоматизированное рабочее место испытаний тепловых труб разрабатывалось и создавалось с целью проведения серии испытаний экспериментальных образцов ГТПС в различных режимах и условиях эксплуатации. На рис. 2 представлено такое рабочее место, в котором для стабилизации температуры применяют жидкостный криостат LOIP FT-311-80. Для перекачки жидкости берут насос перистальтический LOIP LS-30, ГTПС устанавливается на медный водоблок.

В автоматизированном рабочем месте используется прямое измерение температуры с помощью термопар, соединенных с Н-27Т - измерителем милливольтовых сигналов, входящих в состав системы сбора данных LTR27 (рис. 3). LTR27 соединена с персональным компьютером (ПК). Одна термопара находится в зоне конденсации, в данном случае используется термопара хромель - копель. Другая термопара находится в зоне испарения и помещена на противоположную сторону от нагревателя.

Для того чтобы разница температур была измерена точно, обращаются к методу программного обнуления погрешности. Термопары одновременно погружают в емкость с жидко- 
стью, емкость нагревают, при этом данные с термопар записывают в файл и обрабатывают на ПК [8]. Недостатками рабочего места являются:

- общая погрешность системы сбора данных;

- погрешность термопары в зоне конденсации;

- сложность системы охлаждения.

Плотный контакт ГТПС с медным водоблоком обеспечивается термопастой КПТ-8. Рассчитано, что при толщине слоя пасты КПТ-8 в 1 мм температура ГТПС увеличивается на $4{ }^{\circ} \mathrm{C}$. Чтобы исключить влияние термопасты на результаты измерений, термопару плотно прижимают к зоне конденсации ГТПС. Термопара закреплена внутри болта M4 (рис. 4), болт вкручивается в водоблок и проходит его насквозь.

Моделирование в программном обеспечении ANSYS зоны конденсации ГТПС показывает, что расположение термопары влияет на отвод тепла (рис. 5). На термопаре при этом наблюдается большой градиент температуры.

Из профиля температуры на рис. 6 видно, что термопара имеет градиент более $1{ }^{\circ} \mathrm{C}$. Поскольку измерения проводятся в автоматическом режиме, то из расчета исключаются погрешность округления и субъективная погрешность. В качестве оценки систематической погрешности принимают погрешность модульной системы сбора данных LTR27.

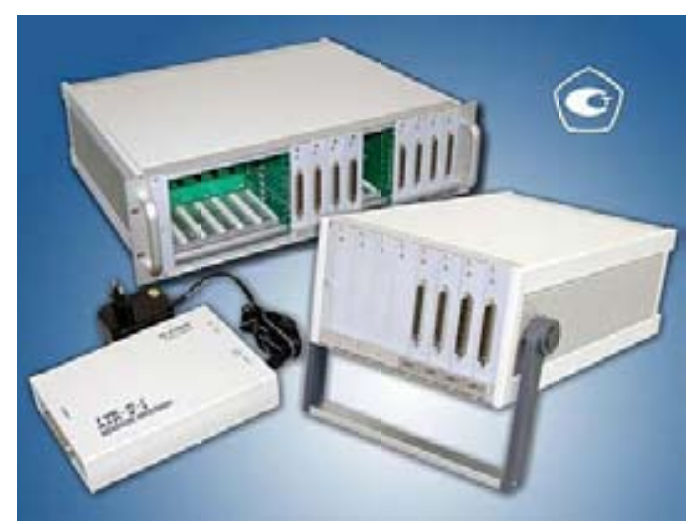

Pис. 3. Модульная система сбора данных LTR27

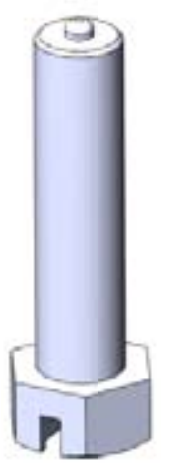

Рис. 4. Термопара внутри болта M4 


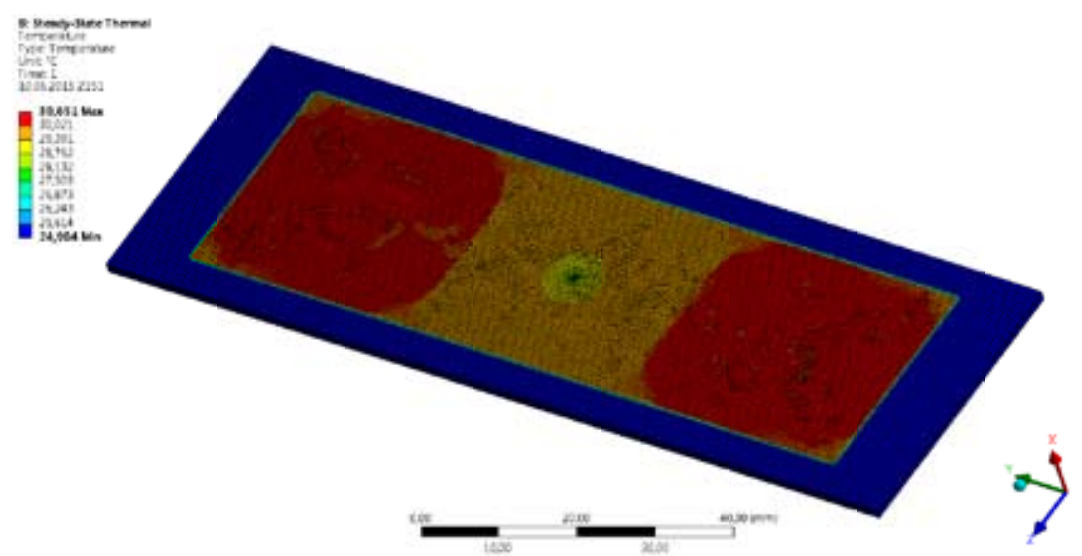

Рис. 5. Профиль температуры под ГТПС
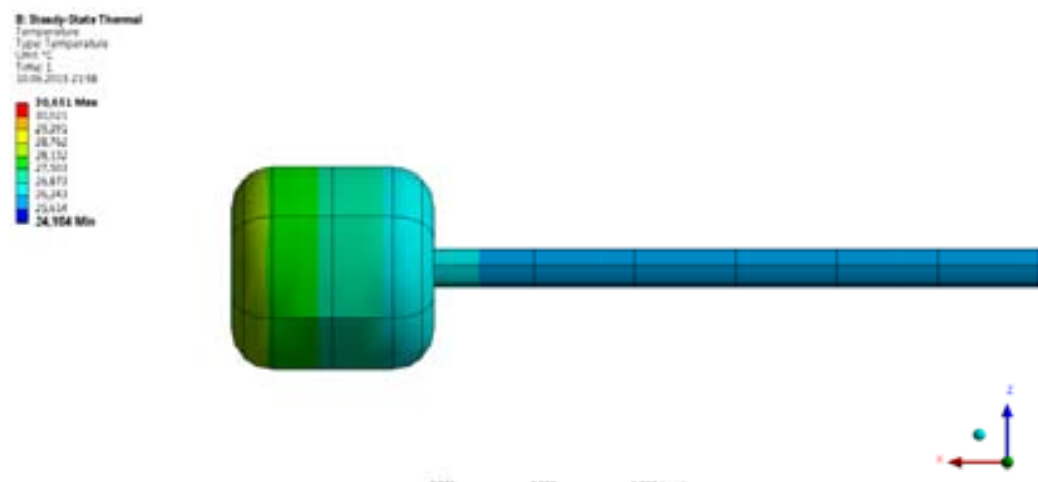

Рис. 6. Профиль температуры термопары в зоне конденсации

Для оцифровки данных в модульной системе сбора данных LTR27 используют три модуля серии Н-27X:

- для оцифровки сигнала с термопар 2 модуля Н-27Т. Диапазон измерения: $-25 \ldots+75$ мВ; предел основной приведенной (к конечному значению диапазона измерения входного сигнала) погрешности - «9\%;

- для оцифровки сигнала с термометра сопротивления H-27R-100. Диапазон измерения $0 \ldots 100$ Ом; предел основной приведенной (к конечному значению диапазона измерения входного сигнала) погрешности - «6 \%. Данные взяты из паспорта изделия;

- стандартное отклонение для оценки погрешности прибора (платы АЦП) находят по формуле

$$
\sigma_{\text {прибора }} \approx \frac{\Delta_{\text {преd }}}{3} .
$$

Откуда имеем

$$
\sigma_{\text {термопары }}=\frac{0,09}{3}=0,03 \mathrm{MB}
$$




$$
\sigma_{\text {терм. сопр. }}=\frac{0,06}{3}=0,02 \text { Ом. }
$$

Коэффициент термоЭДС $\left(\right.$ мкВ $\left./{ }^{\circ} \mathrm{C}\right)$ для термопар типа ТХК (хромель - копель) в диапазоне температур от минус 200 до $600{ }^{\circ} \mathrm{C}$ равен $64-88$ мкВ/ ${ }^{\circ} \mathrm{C}$. Принимаем в расчет среднее значение коэффициента $76 \mathrm{м \kappa В} /{ }^{\circ} \mathrm{C}$. Тогда

$$
\sigma_{\text {термопары }}=(0,03 / 76) \cdot 1000=0,39{ }^{\circ} \mathrm{C} .
$$

Температурный коэффициент термометра сопротивления, определяемый как

$$
\alpha=\frac{R_{100}-R_{0}}{R_{0} \cdot 100^{\circ} \mathrm{C}}
$$

для термометра типа ТСП100 равен $\alpha=« 0391, \mathrm{R} 0=50.1$ Ом. Зависимость сопротивления от температуры окружающей среды в диапазоне от 0 до $100{ }^{\circ} \mathrm{C}$ можно считать линейной, откуда имеем коэффициент термосопротивления $\left(\mathrm{OM} /{ }^{\circ} \mathrm{C}\right)$ :

$$
b=\frac{R_{100}-R_{0}}{100{ }^{\circ} \mathrm{C}}=\alpha \cdot R_{0}=0.196 \mathrm{OM} /{ }^{\circ} \mathrm{C} .
$$

Тогда:

$$
\sigma_{\text {терм.сопр. }}=\frac{0,02}{0,196} \approx 0,1^{\circ} \mathrm{C} .
$$

Так как сигналы с термопар и термометра сопротивления затем складываются, то суммарное стандартное отклонение для оценки погрешности прибора (платы АЦП) может быть вычислено как

$$
\sigma_{\text {сист.сумм. }}=\sqrt{\sigma_{\text {терм. сопр. }}^{2}+2 \cdot \sigma_{\text {термопары }}^{2}} \approx 0,56^{\circ} \mathrm{C} \text {, }
$$

а общая погрешность измерений с проблемами в зоне конденсации ГТПС:

$$
\sigma_{\text {общая }}=\sqrt{\sigma_{\text {сист. сумм. }}^{2}+\sigma_{\text {конденсации }}^{2}} \approx 1,14^{\circ} \mathrm{C} \text {. }
$$

Таким образом, автоматизированное рабочее место имеет погрешность измерений более « ${ }^{\circ} \mathrm{C}$. Стоит отметить, что при измерениях в диапазоне температур от минус 35 до минус $40{ }^{\circ} \mathrm{C}$ криостат системы охлаждения LOIP FT-311-80 работает на максимальной мощности. Требуется отводить от ГТПС тепловой поток, равный 50 Вт.

На основе численного моделирования нами разработана и спроектирована установка, позволяющая более точно измерить разницу температур (рис. 7). Повышение точности измерений связано с результатами моделирования в ANSYS. Так, например, получен следующий результат: слой пасты КПТ-8 между плоской тепловой трубой (ТТ) и ГТПС толщиной до «мм не влияет на температуру ГТПС, а использование термопасты Coollaboratory Liquid PRO3 (теплопроводность 85 Вт/мК) может увеличить толщину слоя до « мм без увеличения температуры ГТПС.

Система охлаждении построена на радиаторе, контактирующем с элементами Пельтье через термопасту КПТ-8. Двухкаскадный модуль Пельтье обеспечивает разницу температур в

$$
-780-
$$


$115^{\circ} \mathrm{C}$. Так как производительность модулей пропорциональна силе тока, возможно управление разницей температур и ее стабилизацией.

В программном обеспечении ANSYS смоделированы основные узлы установки. На рис. 8 представлен график сходимости моделирования обдува радиатора тремя вентиляторами ВН-2. Числа Рейнольдса 22961, Пекле 16268.

Радиатор рабочего места рассеивает с шести элементов Пельтье тепловую мощность 600 Вт. Потоки воздуха со скоростью, равной 0,6 м/с, представлены изоповерхностью на рис. 9.

Программный комплекс ANSYS позволяет решать уравнение Навье - Стокса для переноса массы, импульса и энергии, когда вычисляет перенос тепла в ламинарном потоке. Дополнительно решается уравнение переноса, когда поток турбулентный или когда включен теплообмен излучением.

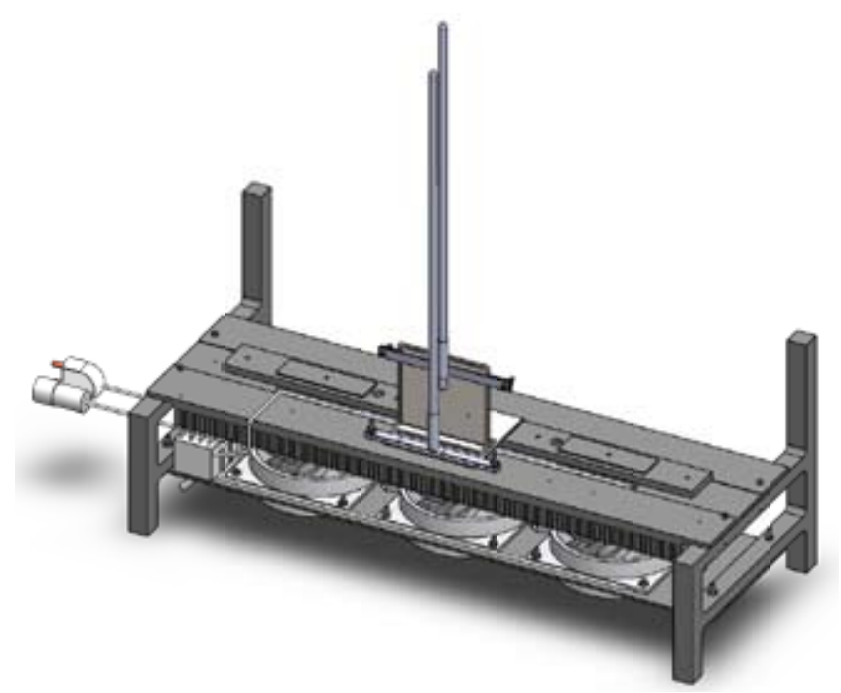

Рис. 7. Новое рабочее место для проверки ГТПС

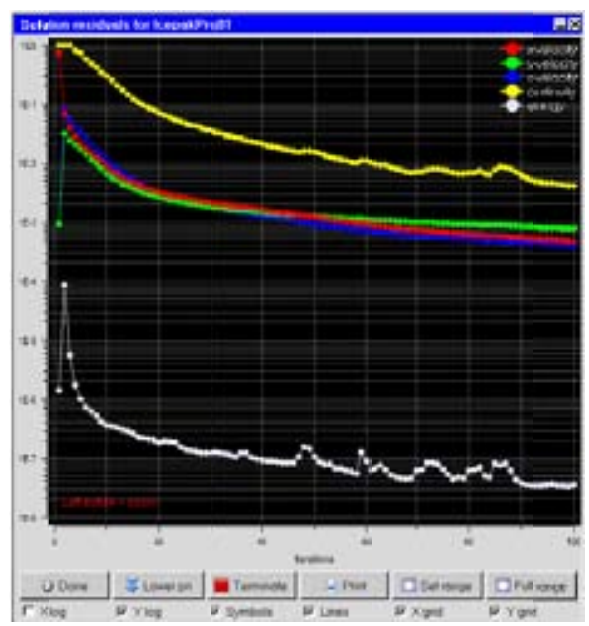

Рис. 8. График сходимости решения 


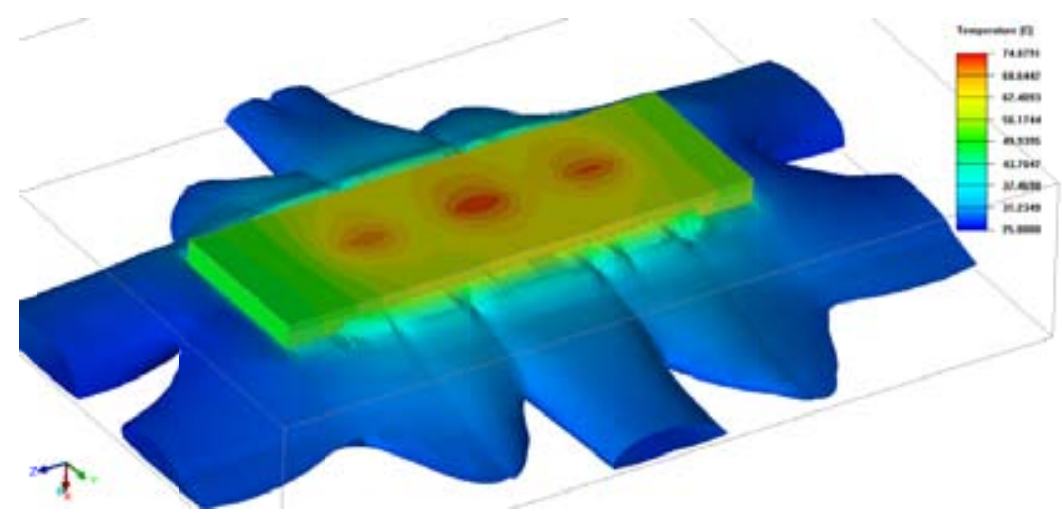

Рис. 9. Профиль температуры радиатора

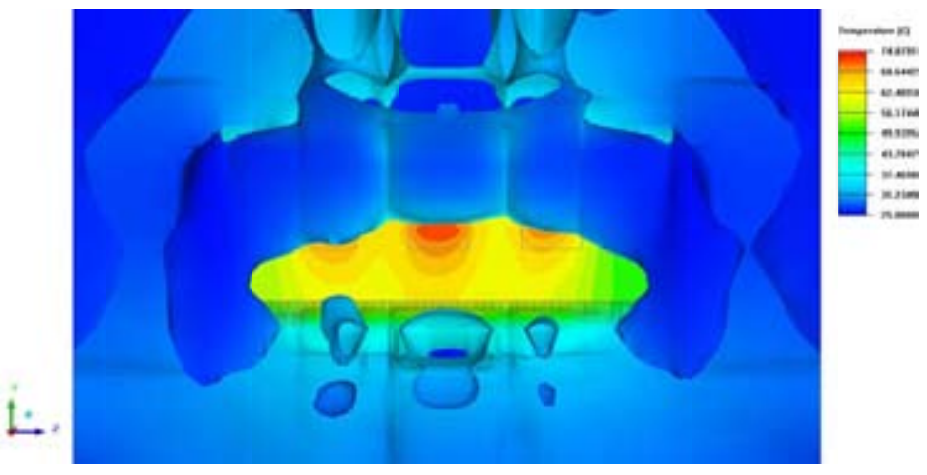

Рис. 10. Изоповерхности воздуха со скоростью « м/с для вертикально расположенного радиатора

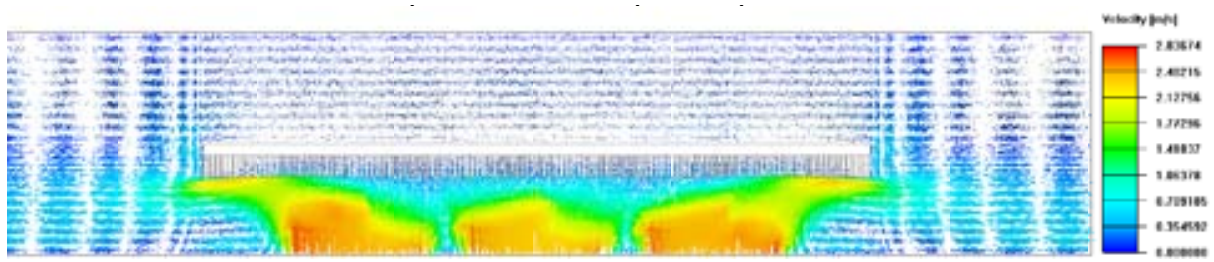

Рис. 11. Распределение скорости воздушных потоков

Уравнение сохранения массы

$$
\frac{\partial \rho}{\partial t}+\nabla \cdot(\rho \vec{v})=0 .
$$

Для несжимаемой жидкости уравнение упрощается:

$$
\nabla \cdot \vec{v}=0
$$

Уравнение сохранение импульса

$$
\begin{gathered}
\frac{\partial}{\partial t}(\rho \vec{v})+\nabla \cdot(\rho \vec{v} \vec{v})=-\nabla p+\nabla \cdot(\overline{\bar{\tau}})+\rho \vec{g}+\vec{F} \\
-782-
\end{gathered}
$$


где $p$-статическое давление, $\overline{\bar{\tau}}$ - тензор напряжения, $\rho \vec{g}$ - гравитационная сила. $\vec{F}$ - содержит другие источники возникающие из сопротивления, энергии.

Тензор напряжения $\overline{\bar{\tau}}$ задан как

$$
\overline{\bar{\tau}}=\mu\left[\left(\nabla \vec{v}-\nabla \vec{v}^{T}\right)-\frac{2}{3} \nabla \cdot \vec{v} I\right]
$$

где $\mu$ - молекулярная вязкость, $I$ - единичный тензор. Второй член уравнения с правой стороны учитывает влияние объемного расширения.

Уравнение сохранение энергии

$$
\begin{aligned}
& \frac{\partial}{\partial t}(\rho h)+\nabla \cdot(\rho h \vec{v})=\nabla\left[\left(k+k_{t}\right) \nabla T\right]+S_{h}, \\
& h=\int_{T_{r e f}}^{T} c_{p} \mathrm{~d} T
\end{aligned}
$$

где $T_{r e f}-29 « 5 \mathrm{~K}, k$-молярная проводимость; $k_{r e f}$ - проводимость, вносимая турбулентным переносом $\left(k_{t}=c_{p} \mu_{t} / P r_{t}\right) ; S_{h}$ - объемный тепловой источник.

Модель турбулентности Zero-Equation для расчета турбулентной вязкости

$$
\mu_{t}=\rho l^{2} \mathbf{S},
$$

где $l$ - средняя длина определяется как $l=\min \left(k d, 0.09 d_{\max }\right) ; d-$ расстояние от стенки; $k-$ константа Вон Кармана $k=0.419 ; \mathbf{S}-$ тензор отношения деформации к начальной длине

$$
\mathbf{S}=\sqrt{2 \mathrm{~S}_{i j} \mathrm{~S}_{i j}}
$$

где $S_{i j}$ - уровень напряжения определяется как

$$
\mathrm{S}_{\mathrm{ij}}=\frac{1}{2}\left(\frac{\partial u_{j}}{\partial x_{i}}+\frac{\partial u_{i}}{\partial x_{j}}\right)
$$

где $u$ - мгновенная скорость.

Измерения производятся по обратной схеме. B ANSYS смоделирована конструкция, состоящая из ГТПС, плоской ТТ, термопасты (рис 12). На зону конденсации ГТПС нанесен слой термопасты Coollaboratory Liquid PRO3 (теплопроводность 85 Вт/мК) толщиной « мм. Плоская ТТ имеет эффективную теплопроводность 20000 Вт/мК. Нагреватель расположен в верхней части ГТПС.

На рис. 12 видно, что плоская ТТ имеет температуру, одинаковую с зоной конденсации ГТПС. В зону справа от ГТПС и в зону испарения ГТПС устанавливаются термометры ТЛ-4 с соответствующего диапазона измерений.

Нормативные и технические документы термометров:

1. ГОСТ 28498-90 «Термометры жидкостные стеклянные. Общие технические требования. Методы испытаний».

2. ГОСТ 8.279-78 «Термометры стеклянные жидкостные рабочие. Методы и средства поверки».

3. ГОСТ 8.558-93 «Государственная поверочная схема для средств измерений температуры».

$$
-783-
$$



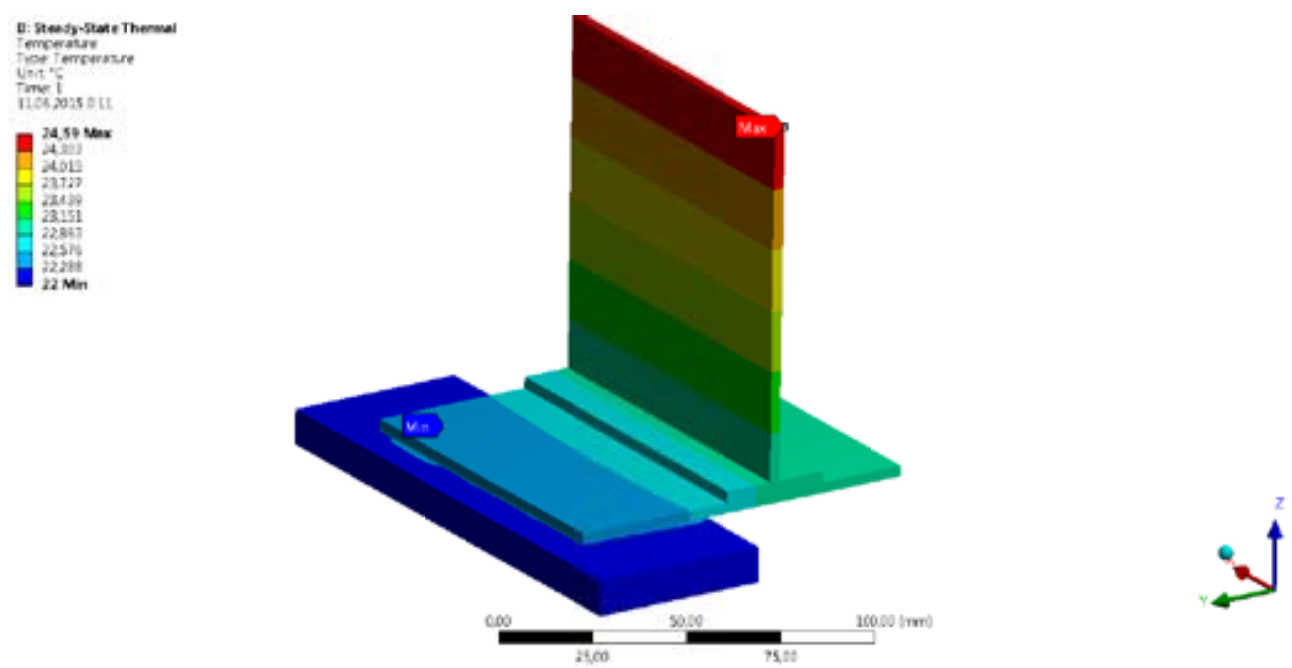

Рис.12. Распределение скорости воздушных потоков

Таблица 2. Основные характеристики лабораторных термометров

\begin{tabular}{|l|c|c|c|c|}
\hline \multicolumn{1}{|c|}{$\begin{array}{c}\text { Обозначение } \\
\text { термометров }\end{array}$} & $\begin{array}{c}\text { Диапазон } \\
\text { измерения, }{ }^{\circ} \mathrm{C}\end{array}$ & Цена деления, ${ }^{\circ} \mathrm{C}$ & Длина, мм не более & Диаметр, мм \\
\hline ТЛ-4 № 1 & от минус 30 до 20 & & 530 & $11 \pm 1$ \\
\cline { 1 - 2 } ТЛ-4 № 2 & от 0 до 55 & « & & \\
\hline ТЛ-4 № 3 & от 50 до 105 & & & \\
\hline
\end{tabular}

4. ТУ 25-2021.003-88 «Термометры стеклянные лабораторные. Технические условия».

Задача состоит в нахождении для данных термометров разницы температур, одновременно погрузив их в жидкость с температурой из диапазона измерений.

\section{Выводы}

Основной результат создания нового рабочего места для испытаний ТТ и ГТПС (см. рис. 7) это обеспечение точности измерений разницы температур с точностью до « ${ }^{\circ} \mathrm{C}$ между зонами конденсации, испарения ГТПС. Второй по важности результат - упрощение системы охлаждения. Следует отметить, что ориентировочная стоимость новой установки по проверке ГТПС в 15-20 раз меньше, чем существующие.

\section{Список литературы}

[1] Деревянко В.А., Нестеров Д.А., Косенко В.Е. и др. // Вестник СибГАУ. 2013. № 6(52). C. 111-116.

[2] Лукс А.Л., Матвеев А.Г. // Вестник СамГУ. Естественнонаучная серия. 2008. № 3(62). C. $331-356$.

[3] Козулин И.А. // Автореф. дис. ... канд. физ.-мат. наук. Новосибирск, 2013. 23 с.

[4] Кузнецов Г.В. Санду С.Ф. // Теплофизика и аэромеханика. 1998. Т.5. № 3. С. 469-477. 
[5] Кузнецов, Г.В. Санду С.Ф. // Special Issue Proceedings of International Conference RDAMM-2001, 2001. Vol. 6. Pt 2. 234-238.

[6] Китаев А.И., Лукс А.Л., Порядин А.В. // Вестник СамГУ. 2009. № 3(19). С. 98-101.

[7] Колоусова А.А. Математическое моделирование теплопереноса в системе «источник тепловыделения - соединительный элемент - тепловая труба». Томск, 2004.

[8] Faghri A. Heat pipe science and technology. Washington: Taylor \& Francis, 1995.

[9] Дач П. Д., Рей Д.А. Тепловые трубы. М.: Энергия, 1979. 